\title{
Research on the Sports Injury in Physical Education
}

\author{
Ling $\operatorname{Han}^{1}$ \\ ${ }^{1}$ Xi'an Medical University, Shannxi, Xi'an, 710021
}

KEYWORDS: Sports Injury; Physical Education; Research

\begin{abstract}
Tennis has become a sport more popular Chinese universities, most colleges and universities have opened sports tennis professional courses. But by the tennis own characteristics and other factors, sports injuries of the project is relatively common, even in the more outstanding sports College students and athletes, injury is inevitable. These sports injuries athletes had a fear of emotion in the game and training, to a certain extent, has affected the normal training. And many people believe that damage is inevitable, for this idea to train elite athletes, coaches and sports teaching workers the responsibility of the sports colleges for great harm.
\end{abstract}

\section{Introduction}

Sports injury refers to a variety of injuries occurring in sports process. It occurs with exercise training, sports technology, sports, sports equipment, and environmental and other factors. Sports injury occurred mainly in the human motor system, but also damage the blood vessels and nervous system, belongs to the category in orthopedic medicine, it is an important part of sports medicine. Study on interested parties to sports injuries mainly through statistical methods, sum up the reasons of injury, damage to the characteristics and regularity of the factors relevant aspects, to provide a scientific basis for the prevention and treatment of sports injuries, improve teaching and training methods to improve athletic performance and guide. Many different types of sports injuries, according to the different point of view can be divided into the following categories: organizational structure is divided by the injury of skin damage, muscle and tendon injuries, joint injuries, bursa damage, bone damage, nerve damage and damage to internal organs and so on; press after injury skin or mucous membrane integrity open-minded and blunt trauma injuries; according to the severity of injury after injury can be divided according to the original plan for training called "minor injuries" and cannot train as planned, we need to stop part of the training after injury or reducing some activities called "moderate injury", cannot exercise called "serious injury"; course of sub-acute injury by injury and chronic wounds.

\section{The Common Types of Injuries in Physical Teaching}

Muscle strain is the most common sports injury in a sport, the main reason it happens is that the body no ability to meet the requirements of the motion, the motion is too intense. In the case of explosive moments, the loss of muscle endurance, resulting in an irresistible destructive effect on muscle tissue, which often occurs in need of some explosive items.

Ankle ligament injury is more common in sports or Sprint, these items on the feet, especially the ankle under pressure too much, and sometimes need to rely entirely ankle ligaments to control the body's balance, so easily cause ankle ligament damage. In many technical action sports, since the motion error, even in case of accidental collision did not happen, it is still likely to cause damage to the joints. 


\section{The Cause of Injury in Physical Education}

Usually to enhance safety education in physical education, to overcome the paralysis of thought, earnestly implement the principle of prevention. Whether teachers or students should take security seriously enough in terms of ideology, the security problem in the first place, especially teachers sure to attract attention in the second extreme ideology.

Warming sports an indispensable part of teaching, but teaching teachers often ignore the preparatory activities, full preparations so that students can reduce the incidence of injury in motion, in pleasant middle school knowledge in a pleasant exercise in. Allow students to correct understanding of the importance of preparatory activities, physical love, and to teach students one or two exercise methods, means, to enable students to enhance the importance of preparatory activities. A survey statistics show that the lack of preparation activity or activities in preparation unreasonable and it is the main cause of sports injuries, not ready activity is the main cause of sports injuries.

Students' physical quality is poor, unskilled technical movements is another important factor in sports injury, the student movement technology control is not good for two reasons: First, poor physical fitness of students, especially the strength, agility, flexibility is poor quality, stiff, uncoordinated, encountered some technical teaching more complex and difficult sport or in the case of exercise, increase the intensity of it is easy to damage. Second, according to the laws of motion forming technology, the generalization stage and differentiation stage in the formation of motor skills, since the student movement is not deep technical understanding of the concept, exercise extra action after technical grasp of instability, in this case also prone to injury.

An important reason for exercise-induced fatigue, mental stress are caused by too much excitement or sports injury, sports injuries mainly in fatigue during exercise, repeated the same action, so that the burden of excessive body parts caused. When learning a new game content or exhibit excessive excitement, prone to injury. Students in practice more difficult operation because of psychological fear, hesitant to do the movements, but also prone to sports injuries.

In physical education, after each practice to eliminate muscle fatigue more quickly, to prevent the local burden is too heavy and the emergence of sports injuries, the interval between the groups to relax is very important. Teaching exercise over-concentration can cause local body burden too heavy to cause sports injuries.

Reasonable teaching methods not only help students quickly and accurately grasp the teaching content, improve the quality of teaching, but also effectively prevent the occurrence of sports injuries. Irrational teaching method is an important factor leading sports injury, to master reasonable teaching methods and correct motion technology, increasing the amount of exercise science.

\section{The Prevention of Sports Injury}

In teaching, so that students from the thought to attach great importance to the prevention of sports injuries, prevention of significance should be fully recognized, only to master the law of sports injuries occur, sum up experience, in order to minimize or avoid sports injuries, thus to ensure that sport participant's health.

Students lifelong physical awareness and develop scientific and systematic method of exercise, so that students understand the role of preparatory activities, preparatory activities fully understand the meaning and purpose; special focus on increasing the proportion of time and preparation activities, combined with teaching content targeted student organizations prepare activities. 
In sport should be excluded from the adverse effects of space, equipment, weather and other factors, to strengthen the organization of physical exercise, sports give students the necessary guidance, but also improve students' physical fitness and motor skills, and strengthen the protection of students self-protection awareness.

In short, as long as the PE teachers in students' ideological emphasis on sports injuries, teaching solid, serious and responsible, strict demands on management, due diligence, care for students, you can reduce or avoid the occurrence of PE Teaching of Sports Injury.

\section{The Treatment Measures of Sports Injury}

In physical education, we must first strengthen the purpose of sex education in sports, and implement prevention-oriented approach to safety education as an important part of the lesson. Multi-channel to carry out school safety education and publicity is very important, because in college physical education, one of the causes of sports injury accident was not strong sense of responsibility of individual teachers; second reason is that some of the students a sense of organization, poor self-protection; Reasons Third, some objective and subjective factors are intertwined. Therefore, the University of Physical Education teachers should take full advantage of dominant position and play the main role of students, active occupation safety education advocacy positions to avoid sports injuries.

Practice has proved that exercise schedule is too large, not only cannot play the role of physical exercise, it will lead to sports injuries. Conversely, if it lack of exercise load arrangements, amounted to less than the promotion of human exercise capacity increase purposes. Therefore, teachers should be strictly in accordance with the principles of sports training, according to the characteristics of the movement, individual treatment, gradual and reasonable arrangements for exercise stress.

Therefore, whether in the usual physical education, or teaching the game, should be fully ready activities. Preparations should note the following three requirements: First, the preparatory activities of the contents of the load; the second is the individual's physical function; Third, the prevailing weather conditions. To make full preparations according to different conditions, easily hurt parts to pay special attention to track the timing of the interval. While adding some strength exercises and stretching exercises to further increase muscle elasticity and prevent muscle strain. No matter what sport, full preparations to ensure that students from damage is the primary means.

Rational organization of teaching practice and competition must be noted that the problem is multifaceted, the former physical education teacher should carefully prepare lessons, to focus on the lesson and difficult injury-prone parts be aware of. After class, the teacher must be from a security point of view, do a good job of teaching organization: requiring students must wear sports shoes and sportswear PE. Sports venues kept clean and free of debris to avoid accidents. Strict checks on class used sports equipment. Standard action essentials, clear motion signal $\backslash$ such as gestures, passwords, etc.]. As long as careful organization and strict requirements, you can minimize or avoid unnecessary strain and abrasions due to technical movements are incorrect, excessive force and other reasons caused.

For hungry students and distinction eat treats, not across the board; for students to have the disease properly arranged; poor technology, poor skills, disobedient students to be aware of. Students of different physical condition, mental state because of significant differences individualized student body, so when the school teachers should be good at observing the student body, the facial expressions. If students appear pale complexion, sweating sounded, walking shaking phenomenon, indicating that students physically frail, should be allowed to rest and observe 
the student changes. Paying particular attention to the afternoon of the last class, because the students fasting, energy, physical strength are not very abundant, should control the exercise should not be too large. Also note that teachers also have some knowledge of sports medicine and simple treatment methods, a problem known to take the right approach for the first time in first aid treatment or treatment to reduce and prevent accidents.

Due to the situation facing the sports complex, as well as factors such as weather conditions and other site equipment, so in teaching must educate students to enhance self-care awareness, to play the subjectivity of students, this is fundamental to actively avoid sports injuries occur. Sports complex, competitive and social, psychological aspects of students' increasingly high demand, some students there are different types of fear, teachers should be good at observing students, communicate with students, do physical exercise to promote its work to eliminate psychological barriers, let them happy and healthy exercise.

\section{Conclusion}

Physical Education campaign against injury prevention is the key, as long as the PE teachers in students' ideological emphasis on sports injuries, using a reasonable method of teaching, teaching full consideration of the human or non-human factors, solid teaching, serious and responsible, strict requirements on the management, due diligence, care for students, it is possible to reduce or avoid the occurrence of sports injury in Physical Education, to ensure the normal sports teaching.

\section{Reference:}

[1] Kuisis SM. Camacho T. Kruger P E. Camacho A L. Self-reported incidence of injuries among ballroom dancers [J]. African Journal for Physical. Heal the Education, Recreation and Dance 2012(18): 107-119,

[2] C lay Miller. MD.MFA. Dance medicine[J].current concepts.2012:107-119.

[3] Lisa M. Griffin \& C.Sue Combs. Student Teachers' Perception of the Role of the Physical Education. JOPERD, 2000, 71(4):42-45.

[4] Kay M. Williamson. A Qualitative Study on the Socialization of Beginning Physical Education Teacher Educators. Research Quarterly for Exercise and sport, 1993, 64(3):188-201. 